Saradaprasan Muduli, Li-Hua Chen, Meng-Pei Li, Zhao-wen Heish, Cheng-Hui Liu, Suresh Kumar*, Abdullah A. Alarfaj, Murugan A. Munusamy, Giovanni Benelli, Kadarkarai Murugan, Han-Chow Wang, Da-Chung Chen, Shih-Tien Hsu, Shih-Chang Chang and Akon Higuchi*

\title{
Stem cell culture on polyvinyl alcohol hydrogels having different elasticity and immobilized with ECM-derived oligopeptides
}

DOI 10.1515/polyeng-2016-0193

Received May 25, 2016; accepted November 1, 2016; previously published online December 9, 2016

\begin{abstract}
The physical characteristics of cell culture materials, such as their elasticity, affect stem cell fate with respect to cell proliferation and differentiation. We systematically investigated the morphologies and characteristics of several stem cell types, including human amniotic-derived stem cells, human hematopoietic stem cells, human induced pluripotent stem (iPS) cells, and embryonic stem (ES) cells on poly(vinyl alcohol) (PVA) hydrogels immobilized with and without extracellular
\end{abstract}

*Corresponding authors: Suresh Kumar, Department of Medical Microbiology and Parasitology, Universiti Putra Malaysia, Serdang 43400, Slangor, Malaysia, e-mail: sureshkudsc@gmail.com; and Akon Higuchi, Department of Chemical and Materials Engineering, National Central University, No. 300, Jhongda Rd., Jhongli, Taoyuan 32001, Taiwan, e-mail: higuchi@ncu.edu.tw; Department of Botany and Microbiology, King Saud University, Riyadh 11451, Saudi Arabia; and Nano Medical Engineering Laboratory, RIKEN, 2-1, Hirosawa, Wako, Saitama 351-0198, Japan

Saradaprasan Muduli, Li-Hua Chen, Meng-Pei Li, Zhao-wen Heish and Cheng-Hui Liu: Department of Chemical and Materials Engineering, National Central University, No. 300, Jhongda Rd., Jhongli, Taoyuan 32001, Taiwan

Abdullah A. Alarfaj and Murugan A. Munusamy: Department of Botany and Microbiology, King Saud University, Riyadh 11451, Saudi Arabia Giovanni Benelli: Department of Agriculture, Food and Environment, University of Pisa, via del Borghetto 80, Pisa 56124, Italy Kadarkarai Murugan: Division of Entomology, Department of Zoology, School of Life Sciences, Bharathiar University, Coimbatore, Tamil Nadu 641046, India

Han-Chow Wang: Hungchi Women and Children's Hospital, No. 233, Yuanhua Rd., Jhongli, Taoyuan 320, Taiwan

Da-Chung Chen: Department of Obstetrics and Gynecology, Taiwan Landseed Hospital, 77, Kuangtai Road, Pingjen City, Taoyuan 32405, Taiwan

Shih-Tien Hsu: Department of Internal Medicine, Taiwan Landseed Hospital, 77, Kuangtai Road, Pingjen City, Taoyuan 32405, Taiwan

Shih-Chang Chang: Department of Surgery, Cathay General Hospital, No.280, Sec. 4, Ren'ai Rd., Da'an Dist., Taipei 10693, Taiwan matrix-derived oligopeptide. Human ES cells did not adhere well to soft PVA hydrogels immobilized with oligovitronectin, whereas they did adhere well to PVA hydrogel dishes with elasticities greater than $15 \mathrm{kPa}$. These results indicate that biomaterials such as PVA hydrogels should be designed to possess minimum elasticity to facilitate human ES cell attachment. PVA hydrogels immobilized with and without extracellular matrix-derived oligopeptides are excellent candidates of cell culture biomaterials for investigations into how cell culture biomaterial elasticity affects stem cell culture and differentiation.

Keywords: biomaterial; cell culture; elasticity; poly(vinyl alcohol); stem cell.

\section{Introduction}

The design and development of biomaterials to facilitate the culture and differentiation of specific cell types are valuable considerations for the advancement of stem cell therapy and the assessment of cancer cell pathology. Human embryonic stem (ES) cells [1] and induced pluripotent stem (iPS) cells [2-4] cannot be cultivated on conventional tissue culture polystyrene (TCPS) plates [5, 6], whereas most cancer cell lines can be cultured on these dishes. Furthermore, it has been reported that human adipose-derived stem cells (hADSCs) within colon cancer tissues can be purified using hydrophilic nanosegment-immobilized surfaces [7]. In addition, human cancer stem cells (i.e. cancer-initiating cells) within colon cancer tissues are specifically suppressed when the cells are isolated from colon cancer cells. Therefore, hADSCs can be isolated from cancer tissue with the depletion of cancer stem cells using hydrophilic nanosegment-immobilized surfaces (i.e. cell-sorting surfaces) [7].

The interactions that form between cells and biomaterials are governed by the biochemical and physical characteristics of the materials [8-13]. The biochemical characteristics of cell culture materials (i.e. the chemical compositions of the materials and 
any biomacromolecule coatings on the materials) have been well investigated. Several specific polymers, such as poly(2-[methacryloyloxy]ethyl dimethyl-[3-sulfopropyl]ammonium hydroxide) [14], poly(aminopropyl methacrylamide) [15], poly(methylvinyl ether-alt-maleic anhydride) [16], and poly(2-(acryloyloxyethyl)trimethylammonium chloride-co-2-(diethylamino)ethylacrylate [17], have been reported to facilitate the expansion of human ES cells when used as cell culture platforms. By contrast, human ES cells cannot be cultured on conventional stiff TCPS dishes. Furthermore, several types of extracellular matrices (ECMs) have been used to coat cell culture dishes to facilitate human ES and iPS cell culture. Recombinant vitronectin [18], CellStart (a mixture of fibronectin and albumin) [19], laminin (LN)-511 [20], and LN-332 [21] have all been found to support human ES and iPS cell culture when coated onto stiff TCPS dishes.

Recently, in addition to the biochemical characteristics of cell culture materials, the physical characteristics of these materials, such as their elasticities, are considered to affect stem cell proliferation and differentiation [8, 22-24]. Engler et al. [22-24] previously studied the differentiation fates of human bone marrow-derived mesenchymal stem cells (hMSCs) after culture on collagen-coated polyacrylamide hydrogels of varying elasticity. The use of soft hydrogels with stiffness similar to that of the brain (approximately $0.3-0.4 \mathrm{kPa}$ ) tended to induce stem cell differentiation into neural cell lineages (e.g. cells expressing $\beta$-III tubulin and P-NFH), whereas the use of stiff hydrogels (approximately $10 \mathrm{kPa}$ ) induced the differentiation of cells expressing myogenic markers (e.g. MyoD) [22]. Furthermore, the use of rigid hydrogels with a stiffness of approximately $35 \mathrm{kPa}$, which is similar to that of collagenous bone, induced hMSCs to differentiate into cells expressing the early osteogenic marker Runx2 [22].

Trappmann et al. [25] cultured human epidermal stem cells on collagen-coated polyacrylamide hydrogels with elasticities ranging from 0.1 to $2300 \mathrm{kPa}$. The cells grown on the gels with low elastic moduli $(0.5 \mathrm{kPa})$ did not form stable focal adhesions and induced differentiation as a result of decreased activation of the extracellular signal-regulated kinase/mitogen-activated protein kinase signaling pathway. By contrast, cell differentiation and spreading were not affected by the elasticity of polydimethylsiloxane (PDMS) after culture on collagen-coated PDMS dishes [25].

Rowlands et al. [26] investigated the myogenic and osteogenic differentiation potential of hMSCs cultured on polyacrylamide hydrogels of varying stiffness that were immobilized with ECM proteins (i.e. fibronectin, laminin, collagen IV, or collagen I). These ECM-coated hydrogels supported the proliferation of hMSCs in a stiffness-dependent manner: high stiffness hydrogels promoted up to a 10 -fold increase in number of cells relative to low stiffness hydrogels. Thus, we found a clear interplay between the stiffness of cell culture materials and the presence of ECM proteins from the expression of myogenic and osteogenic transcription factors in hMSCs.

The majority of researchers who have investigated how the physical characteristics of biomaterials affect stem cell differentiation fate have used polyacrylamide hydrogels $[22,25,26]$. This creates the idea that the effects of the physical characteristics of biomaterials on stem cell fate are only of concern when using polyacrylamide hydrogels. However, there is a current need to develop hydrogels of varying elasticity that possess chemical structures that differ from polyacrylamide. Therefore, in this study, we systematically investigated the morphologies and characteristics of several stem cell types, including human amniotic-derived stem cells (hAFCs), human hematopoietic stem cells (hHSCs), human ES cells, and human iPS cells, as well as human colon cancer (LoVo, CoLo205, and NCU-N1) cells, after culture on hydrogels composed of poly(vinyl alcohol) (PVA) hydrogels that were covalently immobilized with and without several different ECMs or ECM-derived oligopeptides. It is demonstrated that PVA hydrogels of varying elasticity that are or are not immobilized with FN or ECM-derived oligopeptides are suitable for the cultivation of different stem cells and colon cancer cell lines.

\section{Materials and methods}

\subsection{Materials}

Poly(vinyl alcohol-co-vinyl acetate-co-itaconic acid) (PVA) was received from Japan VAM \& Poval Co., Ltd. (AF-17, Sakai, Osaka, Japan). The oligopeptides CS1 (EILDVPST), oligoCOL (GTPGPQGIAGQRGVV), oligoFN (KGGAVTGRGDSPASS), cyclic RGD (cRGD, GACRGDCLGA), and oligoVN (KGGPQVTRGDVFTMP) were purchased from PHJapan (Hiroshima, Japan). TCPS dishes (35-3001; diameter $=3.5 \mathrm{~cm}$ ) were received from Becton Dickinson (Franklin Lakes, NJ, USA).

Human iPS cells, HPS0077, were delivered from the Riken BioResource Center (Tsukuba, Japan). Human ES cells, WA09, were purchased from the WiCell Research Institute, Inc. (Madison, WI, USA). Matrigel (354230) and human fibronectin (FN; 356008) were purchased from BD Biosciences (San Jose, CA, USA). Fetal bovine serum 
(FBS; 04-001-1, lot 551035) was obtained from Biological Industries Ltd. (Kibbutz Beit Haemek, Israel). Ham's F-12 (N4888) medium, MCDB 201 medium, and Dulbecco's modified Eagle's medium (DMEM; D5648) were purchased from Sigma-Aldrich (St. Louis, MO, USA). KnockOut Serum Replacement (10828-028), DMEM/F12 medium (11330-057), Essential 6 medium (A1516401), and Essential 8 medium (A1517001) were received from Life Technologies (Carlsbad, CA, USA). MethoCult (GF H4434), StemSpan CC110 cytokine cocktail, and StemSpan serum-free medium (SFEM) were obtained from STEMCELL Technologies (British Columbia, Canada).

Rabbit antihuman Sox2 antibody (ab5603) was received from Millipore (Merck KGaA, Darmstadt, Germany). Mouse antihuman Oct3/4 antibody (sc-5279) was obtained from Santa Cruz Biotechnology (Dallas, TX, USA). Mouse antihuman SSEA4 antibody (ab16287), mouse antihuman TRA-1-60 antibody (ab16288), and mouse antihuman TRA-1-81 (ab16289) were received from Abcam (Cambridge, MA, USA). Rabbit antihuman alphafetoprotein (AFP) antibody (PA5-21004), mouse antihuman $\beta$-III tubulin antibody (MA1-118), and mouse antihuman Nanog antibody (MA1-017) were obtained from Thermo Fischer Scientific (Rockford, IL, USA). Rabbit antihuman $\alpha$-smooth muscle actin (SMA) antibody (PA5-19465) was received from Life Technologies (Carlsbad, CA, USA).

All other chemicals were of reagent grade and were obtained from Sigma-Aldrich (St. Louis, MO, USA).

\subsection{Preparation of cross-linked PVA hydrogel dishes}

Cross-linked PVA hydrogels were prepared according to previous studies (Figure 1) [27-29]. Briefly, PVA having
$1.2-1.3 \mathrm{~mol} \%$ itaconic acid (a hydrolysis degree $=97.2 \%$ ) was dissolved to $0.04-0.05 \mathrm{wt} \%$ in pure water [27]. The PVA solution was then added to TCPS dishes and dried for 6-8 days to produce PVA films. The PVA films were inserted into an aqueous cross-linking solution composed of $1.0 \mathrm{wt} \% \mathrm{H}_{2} \mathrm{SO}_{4}, 20.0 \mathrm{wt} \% \mathrm{Na}_{2} \mathrm{SO}_{4}$, and $1.0 \mathrm{wt} \%$ glutaraldehyde for $0.5,1,6,12,24$, and $48 \mathrm{~h}$. The naming convention "P-Xh" (e.g. P-24h) means PVA hydrogels cross-linked for $X$ hours (e.g. 24 h). After cross-linking, the PVA hydrogels were cleaned with pure water and then sterilized via immersion in a $74 \%-75 \%(\mathrm{v} / \mathrm{v})$ ethanol solution for $0.5 \mathrm{~h}$. After this, the hydrogels were rinsed in pure water and then stored in pure water until usage.

\subsection{Preparation of PVA hydrogel dishes immobilized with fibronectin and ECM-derived oligopeptides}

After the preparation of PVA hydrogels having different stiffness (elasticity), the hydrogels were activated via insertion in an aqueous solution, including $10.0 \mathrm{mg} / \mathrm{ml} \mathrm{N}$-hydroxysuccinimide and $10.0 \mathrm{mg} / \mathrm{ml} \mathrm{N}$-(3dimethylaminopropyl)- $N^{\prime}$-ethylcarbodiimide hydrochloride for $6 \mathrm{~h}$ at $4^{\circ} \mathrm{C}$ [27]. Subsequently, the PVA hydrogels were rinsed with phosphate-buffered saline (PBS; $\mathrm{pH}$ 7.2) and inserted in a PBS solution containing either $100 \mu \mathrm{g} / \mathrm{ml}$ of fibronectin (FN) or $50-1000 \mu \mathrm{g} / \mathrm{ml}$ of ECM-derived oligopeptides (CS1, oligoVN, oligoFN, oligoCOL, or cRGD) for $24 \mathrm{~h}$ at $4^{\circ} \mathrm{C}$ (Figure 1). After the grafting of fibronectin or the ECM-derived oligopeptides, the PVA hydrogels were rinsed with pure water for $12 \mathrm{~h}$ to remove any residual fibronectin or ECM-derived oligopeptides. The PVA hydrogels immobilized with FN or ECM-derived oligopeptides

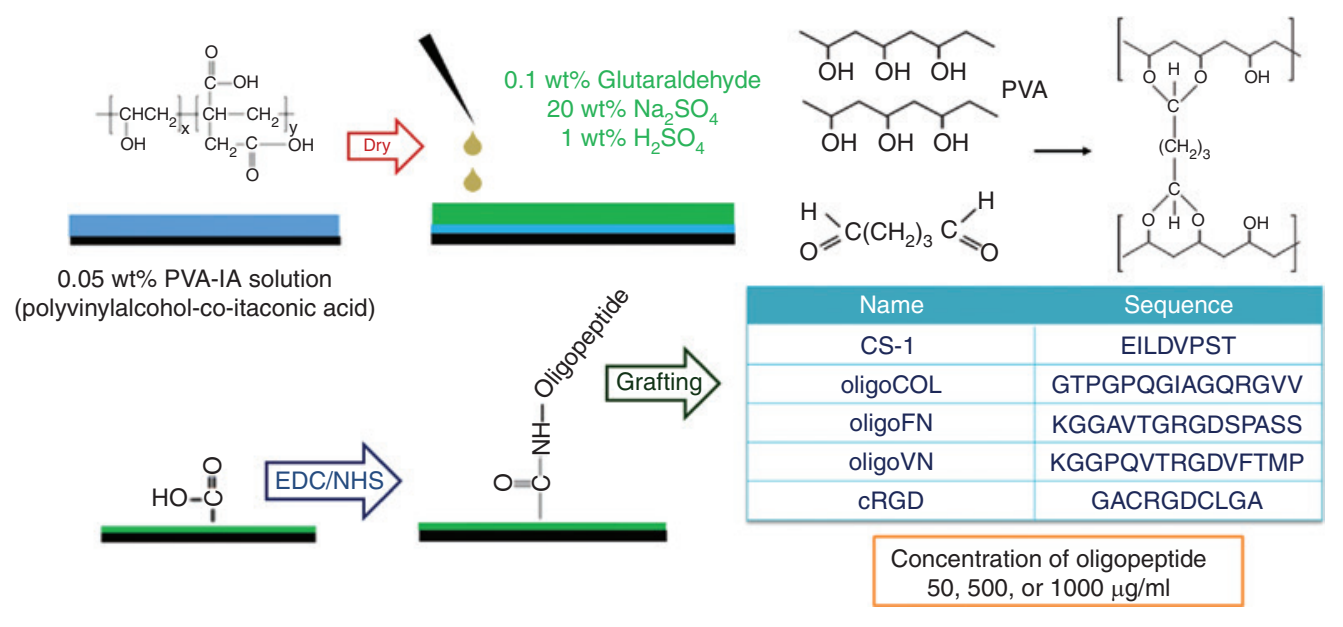

Figure 1: Preparation and reaction schemes of PVA hydrogels immobilized with ECM proteins and ECM-derived oligopeptides. 
are hereafter called P-Xh-FN, P-Xh-CS1, P-Xh-oligoFN, $\mathrm{P}-X \mathrm{~h}$-cRGD, P-Xh-oligoCOL, and P-Xh-oligoVN, where $X$ indicates the cross-linking time (h). X-ray photoelectron spectrophotometer (XPS; K-Alpha spectrometer; Thermal Scientific, Inc., Amarillo, TX, USA) was used for the evaluation of the chemical compositions on the PVA hydrogel dishes.

\subsection{Preparation and culture of cells}

The experiments in this study were approved by the ethics committees of the Cathay Medical Research Institute (CT099012), the Taiwan Landseed Hospital (IRB-1305), and the National Central University. All experiments were performed in accordance with all applicable and relevant institutional and governmental regulations and guidelines.

The human colon cancer cell line LoVo (BCRC 60148; Food Industry Research and Development Institute, Hsinchu, Taiwan) was cultivated on PVA hydrogels or TCPS dishes in Ham's F-12 medium supplemented with 20\% FBS using conventional cell culture protocols [7].

The human colon cancer cell lines Colo205 (BCRC 60054, Food Industry Research and Development Institute) and Colo-NCU1, which were established in our laboratory, were cultured on PVA hydrogels or TCPS dishes in DMEM/F12 medium supplemented with 20\% FBS, 4-(2-hydroxyethyl)piperazine-1-ethanesulfonic acid, sodium pyruvate, and L-glutamine using conventional cell culture protocols [7]. The initial cell seeding density was fixed to $10^{5}$ cells $/ \mathrm{cm}^{2}$. The media were exchanged twice a week. Antibiotics of amphotericin B $(0.625 \mu \mathrm{g} / \mathrm{ml})$, streptomycin $(250 \mu \mathrm{g} / \mathrm{ml})$, and penicillin (250 U/ml) (03-033-1B, Biological Industries, Israel) were also supplemented into the cultivation media.

Fresh second-trimester amniotic fluid was centrifuged at 1100-1200 rpm for $5 \mathrm{~min}$, and the supernatant was removed. After centrifugation, the cells was dissolved in DMEM/MCDM 201 (40\%/60\%) with $10.0 \mathrm{ng} / \mathrm{ml}$ FGF-2 and 20\% FBS, and the cells were cultured in a $\mathrm{CO}_{2}^{-}$ supplemented incubator $(5 \%)$ at $37^{\circ} \mathrm{C}$ [30]. After reaching approximately $82 \%-85 \%$ confluence, the hAFCs were harvested using a trypsin/ethylene diamine tetraacetic acid (EDTA) solution, after which they were centrifuged and inoculated into cell culture dishes using a conventional passage procedure. As passage 4, the hAFCs were cultivated on PVA hydrogels immobilized with ECM-derived oligopeptides or $\mathrm{FN}$ in a $\mathrm{CO}_{2}$ incubator at $37^{\circ} \mathrm{C}$ for $6-7$ days; a subset of cells was also cultured on TCPS dishes under the same conditions.
Mononuclear cells were obtained from human umbilical cord blood using the Ficoll-Paque method [27, 31], and hHSCs (CD34+ cells) were subsequently isolated from the mononuclear cells using an immunomagnetic separation kit and a MiniMacs column (Miltenyi Biotec, BergischGladbach, Germany) for $\mathrm{CD} 4^{+}$cells isolation following the manufacturer's instructions. After elution from the MiniMacs column, the cells were rinsed five times with PBS containing 2-2.1 mM EDTA. The purity of the CD34+ cells was evaluated using flow cytometry.

hHSCs (CD34 ${ }^{+}$cells) were inoculated onto PVA hydrogel dishes immobilized with FN or ECM-derived oligopeptides at a seeding density of $1500 \mathrm{hHSCs} / \mathrm{cm}^{2}$ and then cultured in StemSpan SFEM serum-free culture medium with cytokine cocktail (StemSpan CC110). The medium was supplemented with $0.1 \% \mathrm{wt} / \mathrm{wt}$ low-density lipoprotein following the manufacturer's instructions [27]. The hHSCs were then cultivated for 10 days in a $\mathrm{CO}_{2}$-supplemented incubator $\left(5 \% \mathrm{CO}_{2}\right)$ at $37^{\circ} \mathrm{C}$.

The human WA09 (H9) ES cells were cultivated as previously described on mitomycin-C-treated mouse embryonic fibroblast feeder cells in DEME/F12 medium supplemented with 20\% KnockOut Serum Replacement $[28,32]$. The WA09 cells were then shifted to culture on Matrigel in Essential 8 medium as previously described $[28,32]$. The HS0077 human iPS cells were cultivated on Matrigel in Essential 8 medium [28, 32]. Near-confluent cell clusters were treated with dispase for $1-2 \mathrm{~min}$ at $37^{\circ} \mathrm{C}$. Cells in Essential 8 medium were pipetted to achieve complete dispersal. After centrifugation at 150-160 $\mathrm{g}$ for $4-5 \mathrm{~min}$ at $4^{\circ} \mathrm{C}-5^{\circ} \mathrm{C}$, the cells were inoculated at an appropriate density $\left(5 \times 10^{4}\right.$ cells $\left./ \mathrm{cm}^{2}\right)$ into new culture dishes (PVA hydrogels immobilized with oligoVN). The medium was changed daily during human iPS and ES cell culture experiments.

\subsection{Immunostaining of protein markers involved in differentiation and pluripotency of stem cells}

Stem cells were immunostained for Nanog, Sox2, Oct3/4, Tra-1-81, Tra-1-60, SSEA4, AFP, SMA, and $\beta$-III tubulin following a conventional protocol [33, 34]. To accomplish this, cells grown on dishes were fixed with paraformaldehyde and then incubated with a primary antibody at a 1:110 dilution. Subsequently, the cells were rinsed with PBS and incubated with a secondary antibody at a 1:55 dilution. The cells were also stained with Hoechst 33342 $(1: 55)$. The stained cells were observed using a fluorescence microscope equipped with appropriate filters. 


\subsection{Embryoid body formation}

Human ES cell pluripotency was investigated based on embryoid body (EB) formation at passage 10. To accomplish this, human ES cells were dissociated from their culture dishes, and cells in the supernatant were collected and injected onto ultralow attachment plates in Essential 6 medium to generate EBs. After 15-16 days in suspension, the EBs were shifted to Matrigel-coated plates and cultivated in Essential 6 medium for 4-6 weeks. Then the cells were immunostained with antibodies against protein markers of three embryonic germline layers ( $\beta$ IIITubulin, SMA, and AFP) and evaluated for immunofluorescence [28].

\subsection{Statistical analysis}

Quantitative data were analyzed from three different samples. The data were shown as the mean \pm SD. Statistical analyses were evaluated using an unpaired Student's t-test in Excel (Microsoft Corporation). Probability values (p) less than 0.05 were considered statistically significant.

\section{Results}

\subsection{Physical characteristics of PVA hydrogels immobilized with and without FN or ECM- derived oligopeptides}

PVA hydrogels having different stiffness were immobilized with and without FN or ECM-derived oligopeptides; hydrogel elasticity was modulated by regulating the crosslinking time (intensity). The storage moduli, $E^{\prime}$, of PVA hydrogels with an approximate 20-36 $\mu$ m thickness were measured using a rheometer, and the values are listed in Table 1. The softest PVA hydrogels in the present study,

Table 1: Characteristics of PVA hydrogels.

\begin{tabular}{lrr}
\hline Hydrogels & Storage modulus $E^{\prime}(\mathbf{k P a})$ & Water content (\%) \\
\hline P-0.5h & $3.7 \pm 0.4$ & $85 \pm 3$ \\
P-1h & $10.5 \pm 1.1$ & $76 \pm 3$ \\
P-6h & $13.2 \pm 1.2$ & $62 \pm 3$ \\
P-12h & $18.3 \pm 1.5$ & $52 \pm 2$ \\
P-24h & $25.4 \pm 2.1$ & $47 \pm 2$ \\
P-48h & $30.2 \pm 2.8$ & $44 \pm 2$ \\
TCPS & $\left(3,000,000-1,2000,000^{\mathrm{a}}\right)$ & 0 \\
\hline
\end{tabular}

aElastic moduli $(\mathrm{kPa})$.
P-0.5h, had an $E^{\prime}$ of $3.7 \mathrm{kPa}$. P-1h, P-6h, P-12h, and P-24h hydrogels had $E^{\prime}$ values of $10.5,13.2,18.3$, and $25.4 \mathrm{kPa}$, respectively, whereas the $E^{\prime}$ of the hardest PVA hydrogels in present study, P-48h, was $30.2 \mathrm{kPa}$. TCPS dishes have been reported to have their elastic moduli of 3-12 GPa [27]. The storage moduli of PVA hydrogels immobilized with FN (P-Xh-FN) or ECM-derived oligopeptides (P-Xh-CS1, P-XhcRGD, P-Xh-oligoCOL, P-Xh-oligoFN, and P-Xh-oligoVN) were measured to be the same as those of the corresponding unmodified PVA hydrogels (P-Xh). This similarity exists because the layers of FN or ECM-derived oligopeptides immobilized onto the PVA hydrogels were too thin to contribute to the bulk $E^{\prime}$ values of the PVA hydrogels.

The thickness of the PVA hydrogels in the dishes in water was evaluated to be $2.1-3.0 \mu \mathrm{m}$. Water content $(H)$ is defined in the following equation:

Water content $(H)=$ weight of water in hydrogel $(\mathrm{g}) /$ weight of hydrogel $(\mathrm{g}) \times 100(\%)$.

The water contents of the various PVA hydrogels are also summarized in Table 1. The water content was found to decrease as the cross-linking time used to create the hydrogels increased.

\subsection{XPS analysis of nanosegments immobilized onto PVA hydrogels}

It is important to evaluate the existence of nanosegments (i.e. ECM-derived oligopeptides) and the surface densities of such nanosegments on PVA hydrogels immobilized with ECM-derived oligopeptides with different stiffness. Because it was difficult to evaluate the absolute quantities of nanosegments immobilized onto the PVA hydrogel dishes created in this study via chemical titration and reaction methods, we used XPS to evaluate ECM-derived oligopeptides on the surfaces of the hydrogels. Figure 2A describes the high-resolution XPS spectra of N1s peaks on the surface of $\mathrm{P}-\mathrm{X} \mathrm{h}$-oligoVN, which had $E^{\prime}$ values ranging from 10.5 to $30.2 \mathrm{kPa}$ when the grafting concentration of oligoVN was $500 \mu \mathrm{g} / \mathrm{ml}$. An N1s peak of approximately $400 \mathrm{eV}$ was extensively detected in the P-Xh-oligoVN hydrogel $(X=1,6,12,24$, and $48 \mathrm{~h})$ dishes. The atomic ratios of $\mathrm{N} / \mathrm{C}$ on the surfaces of the $\mathrm{P}-\mathrm{Xh}$-oligoVN hydrogels were evaluated. Similar N/C ratios, 0.14, were obtained on the surfaces of all assessed P-Xh-oligoVN hydrogels $(X=1,6,12,24$, and $48 \mathrm{~h})$, as shown in Figure 2B $(p>0.05)$. These results suggest that the surface density of oligoVN does not depend on P-XholigoVN hydrogel elasticity when the grafting concentration of oligopeptide is kept constant (i.e. $500 \mu \mathrm{g} / \mathrm{ml}$ in this study). 
A
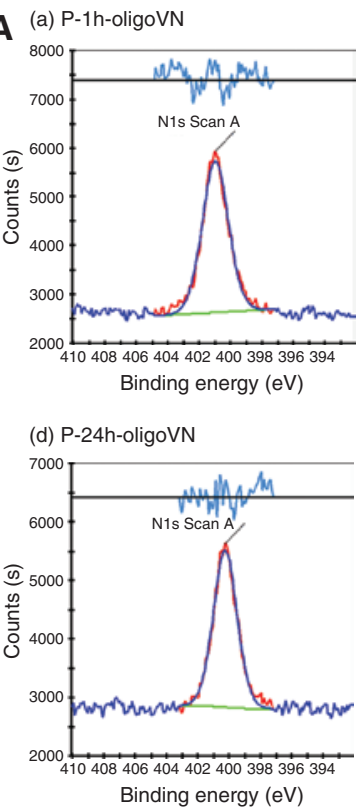
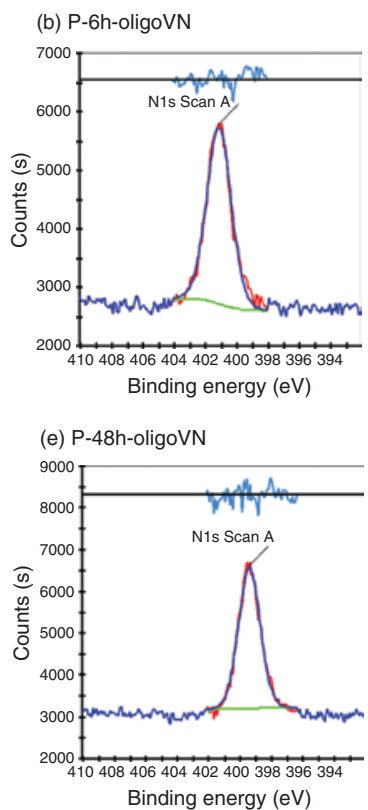
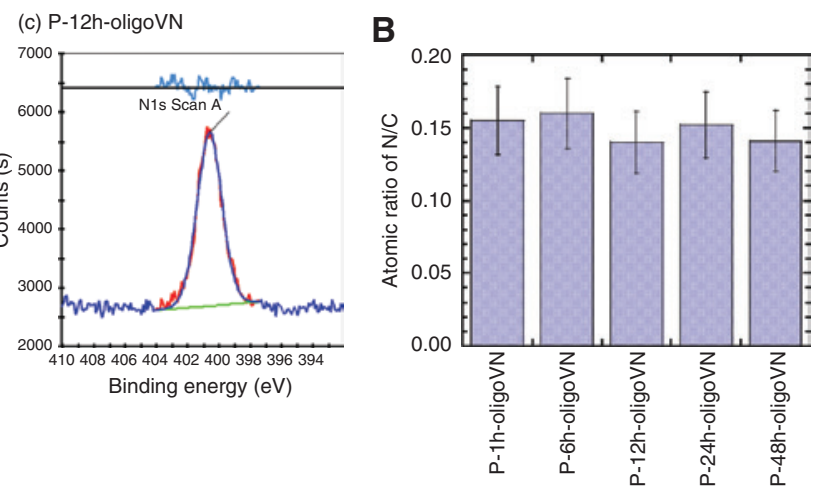

Figure 2: Characterization of PVA hydrogels immobilized with vitronectin-derived oligopeptides (oligoVN). (A) High-resolution XPS spectra of the N1s peaks obtained from the surfaces of P-1h-oligoVN (a), P-6h-oligoVN (b), P-12h-oligoVN (c), P-24h-oligoVN (d), and P-48h-oligoVN (e) hydrogels. (B) The atomic ratios of nitrogen to carbon (N/C) on the surfaces of the P-1h-oligoVN, P-6h-oligoVN, P-12h-oligoVN, P-24h-oligoVN, and P-48h-oligoVN hydrogels.

The atomic ratios of N/C on the surfaces of P-24h-oligoVN hydrogels, which were prepared with oligoVN grafting concentrations of $50-1500 \mu \mathrm{g} / \mathrm{ml}$, were also evaluated. The atomic ratios of $\mathrm{N} / \mathrm{C}$ increased as the grafting concentration increased to $500 \mu \mathrm{g} / \mathrm{ml}$. However, no significant differences (within the experimental error) in the atomic ratio of $\mathrm{N} / \mathrm{C}$ were observed on the surfaces of $\mathrm{P}-24 \mathrm{~h}$-oligoVN hydrogels exposed to oligoVN grafting concentrations of more than $500 \mu \mathrm{g} / \mathrm{ml}(\mathrm{p}>0.05)$. These data are concordant with those in previous reports [30]. On the basis of the previously mentioned results, human ES cells were cultured on P-Xh-oligoVN hydrogels $(X=1,6,12,24$, and $48 \mathrm{~h}$ ) with oligoVN grafting concentrations of 500 or $1000 \mu \mathrm{g} / \mathrm{ml}$ to maintain their pluripotency, whereas colon cancer cells, hAFCs, and hHSCs were cultured on P-oligoECM dishes with oligopeptide grafting concentrations of 50 or $100 \mu \mathrm{g} / \mathrm{ml}$. This strategy reduced the use of expensive oligopeptides in the following experiments.

\subsection{Culture of colon cancer cell lines on PVA hydrogels immobilized with and without oligoVN}

Colo205, LoVo, and Colo-NCU1 colon cancer cell lines were cultured on PVA hydrogels with different stiffness. These hydrogels were not initially immobilized with FN or ECM-derived oligopeptides. The morphologies of the different cell types after 10 days in culture on the hydrogels are shown in Figure 3. The number of Colo205 cells growing on the PVA hydrogels increased as the hydrogel elasticity increased (Figure 3). The numbers of Colo-NCU1 and LoVo cells growing on the hydrogels also increased the hydrogel elasticity increased; however, the overall numbers of attached Colo-NCU1 and LoVo cells were much less than that of the Colo205 cells. The LoVo, Colo205, and Colo-NCU1 cells could all be successively cultured to confluence on conventional, stiff TCPS dishes.

When an ECM-derived oligopeptide (i.e. oligoVN) was immobilized onto PVA hydrogels (Figure 4), the cell attachment of LoVo, Colo205, and Colo-NCU1 cells improved. The numbers of CoLo205 and LoVo cells that successfully grew on P-24h-oligoVN were similar to those of cells grown on TCPS dishes. In addition, we found that colon cancer cells preferentially proliferate on stiffer PVA hydrogels, regardless of whether they were immobilized with oligoVN.

\section{4 hHSC and hAFC culture on P-ECM and P-oligoECM hydrogels}

hHSCs were cultivated on PVA hydrogels with different elasticities (P-Xh, P-Xh-FN, and P-Xh-CS1) immobilized 

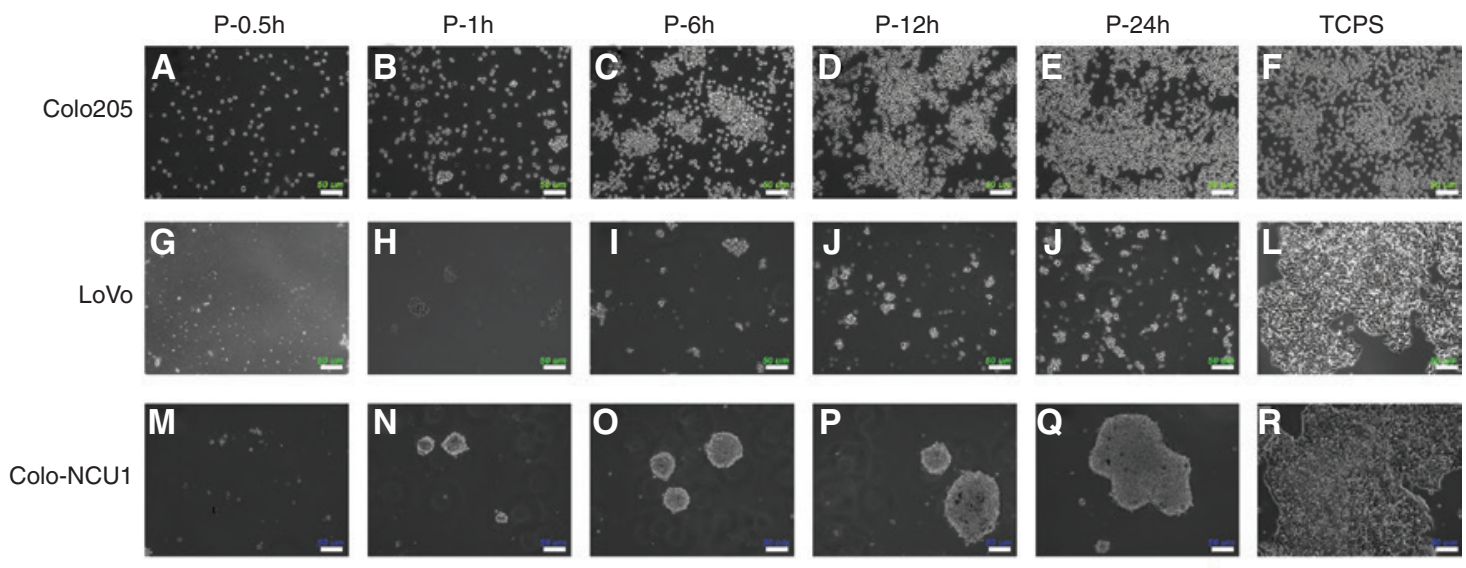

Stiff

Figure 3: Morphologies of human colon cancer cells [CoLo205 (A-F), LoVo (G-L), and Colo-NCU1 (M-R) cells] cultured on unmodified P-0.5h (A, G, M), P-1h (B, H, N), P-6h (C, I, O), P-12h (D, J, P), and P-24h (E, K, Q) hydrogels and on TCPS dishes (F, L, R) after 10 days in culture. The bar indicates $50 \mu \mathrm{m}$.
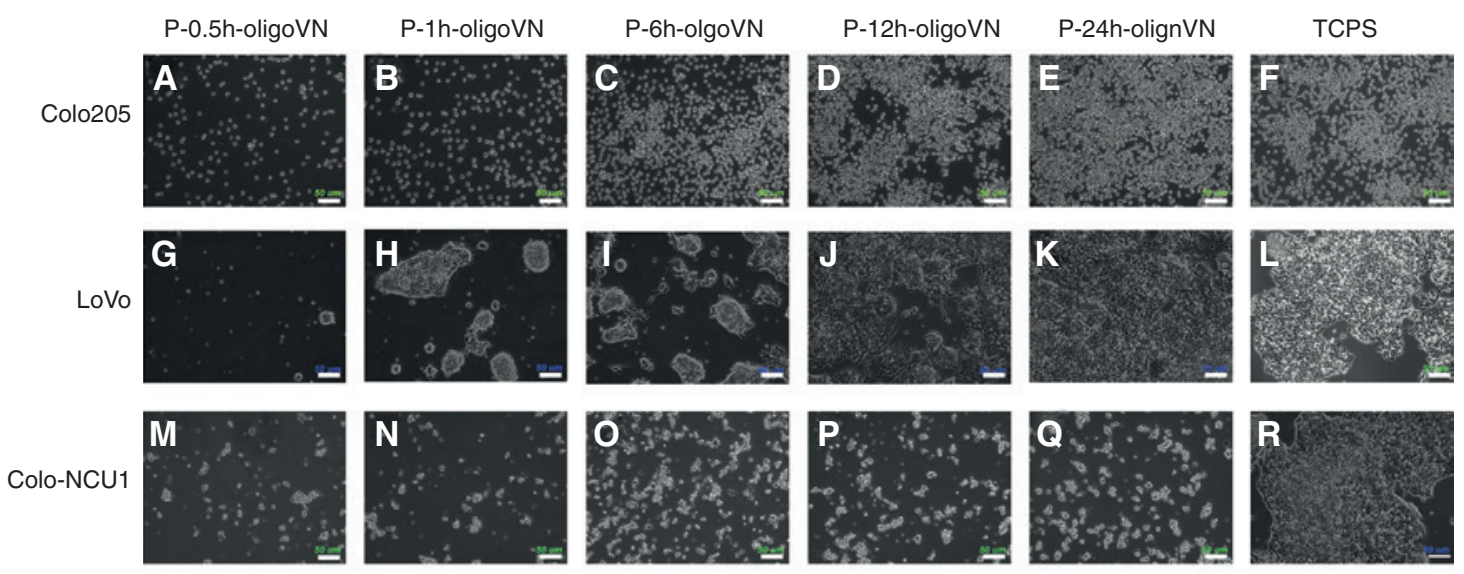

Soft

Stiff

Figure 4: Morphologies of human colon cancer cells [CoLo205 (A-F), LoVo (G-L) and Colo-NCU1 (M-R) cells] cultured on P-0.5h-VN (A, G, M), P-1h-VN (B, H, N), P-6h-VN (C, I, O), P-12h-VN (D, J, P), and P-24h-VN (E, K, Q) hydrogels immobilized with oligoVN and on TCPS dishes (F, L, R) after 10 days in culture. The $\mathrm{P}$-Xh-oligoVN hydrogels were prepared using an oligoVN concentration of $50 \mu \mathrm{g} / \mathrm{ml}$. The bar indicates $50 \mu \mathrm{m}$.

with FN and FN-derived oligopeptides (CS1) because FN and CS1 have been reported to facilitate hHSC expansion $[27,35,36]$. Figure 5 represents the morphologies of hHSCs cultivated on P-Xh, P-Xh-FN, and P-Xh-CS1 hydrogels with elasticities of $E^{\prime}=3.7 \mathrm{kPa}(0.5 \mathrm{~h}$ cross-linking time), $10.5 \mathrm{kPa}$ ( $1 \mathrm{~h}$ of cross-linking time), $13.2 \mathrm{kPa}$ (6 $\mathrm{h}$ of cross-linking time), $18.3 \mathrm{kPa}$ (12 h of cross-linking time), $25.4 \mathrm{kPa}$ (24 h of cross-linking time), and $30.2 \mathrm{kPa}$ ( $48 \mathrm{~h}$ cross-linking time) as well as on TCPS plates (elastic moduli $=3-12 \mathrm{GPa}$ ) after 10 days in culture. The hHSCs were found to proliferate on PVA hydrogels immobilized with and without FN or CS1. Furthermore, the numbers of cells growing on unmodified PVA, FN-immobilized PVA, and CS1-immobilized PVA hydrogels were found to be similar to that of cells grown on TCPS plates.

hAFCs were also cultivated on PVA hydrogels with different stiffness (unmodified PVA, cRGD-immobilized PVA, oligoCOL-immobilized PVA, oligoFN-immobilized PVA, and oligoVN-immobilized PVA) and TCPS plates. Figure 6 describes the morphologies of hAFCs cultivated on unmodified PVA and PVA immobilized with ECMderived oligopeptides with elasticities of $E^{\prime}=13.2-30.2$ $\mathrm{kPa}$, as well as of cells grown on TCPS dishes (elastic moduli $=3-12 \mathrm{GPa}$ ). Figure 7 shows the doubling times of hAFCs cultured on unmodified PVA and PVA immobilized with ECM-derived oligopeptides. 


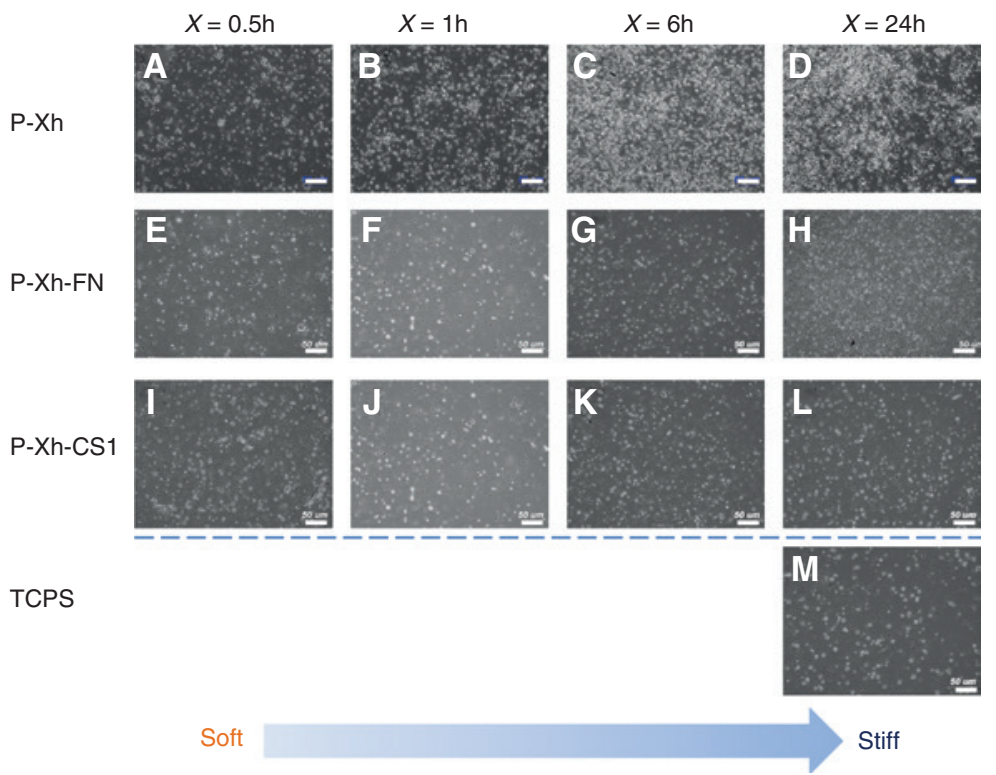

Figure 5: Morphologies of hHSCs cultured on P-Xh hydrogels [P-0.5h (A), P-1h (B), P-6h (C), and P-24h (D)], P-Xh-FN hydrogels [P-0.5hFN (E), P-1h-FN (F), P-6h-FN (G), and P-24h-FN (H)], P-Xh-CS1 hydrogels [P-0.5h-CS1 (I), P-1h-CS1 (J), P-6h-CS1 (K), and P-24h-CS1 (L)], and TCPS dishes $(M)$ after 4 days in culture. The P-Xh-oligoFN and P-Xh-CS1 hydrogels were prepared using oligoFN and CS1 concentrations of $100 \mu \mathrm{g} / \mathrm{ml}$. The bar indicates $50 \mu \mathrm{m}$.

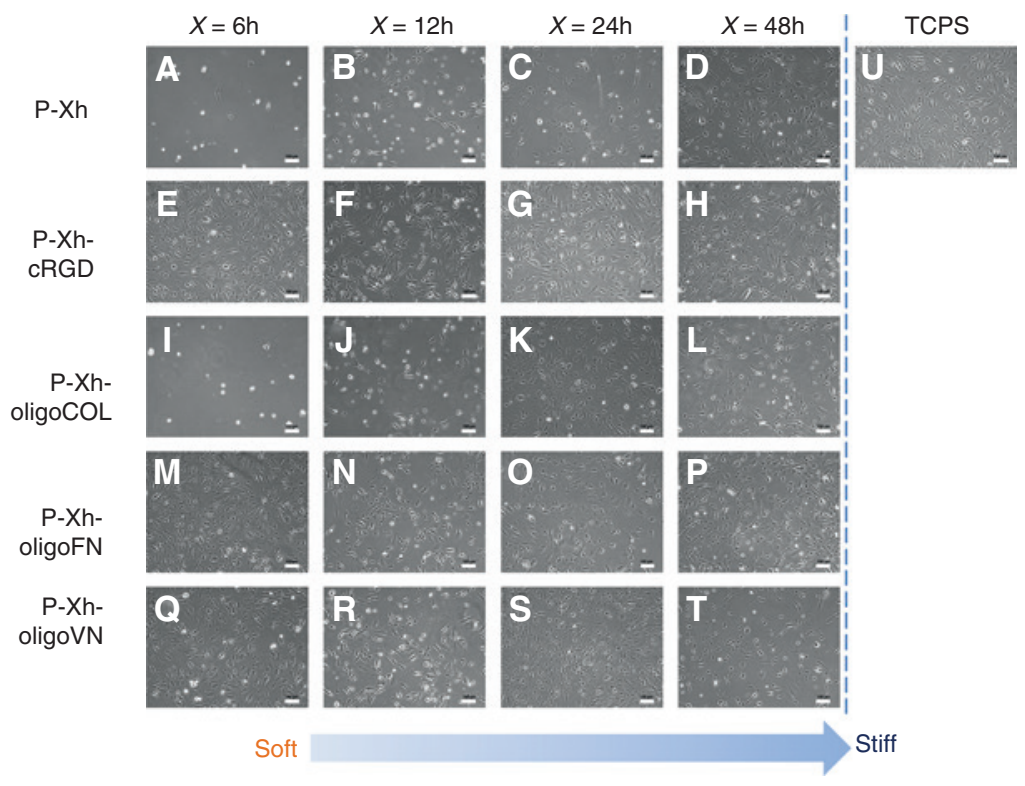

Figure 6: Morphologies of hAFCs cultured on P-Xh [P-6h (A), P-12h (B), P-24h (C), and P-48h (D)], P-Xh-cRGD [P-6h-cRGD (E), P-12h-cRGD (F), P-24h-cRGD (G), and P-48h-cRGD (H)], P-Xh-oligoCol [P-6h-oligoCOL (I), P-12h-oligoCOL (J), P-24h-oligoCOL (K), and P-48h-oligoCOL (L)], P-Xh-oligoFN [P-6h (M), P-12h (N), P-24h (O), and P-48h (P)], and P-Xh-oligoVN [P-6h-oligoVN (Q), P-12h-oligoVN (R), P-24h-oligoVN (S), and P-48h-oligoVN (T)] hydrogels and on TCPS (U) dishes after 7 days of cultivation. The P-Xh-CRGD, P-Xh-oligoCOL, P-Xh-oligoFN, and P-XholigoVN hydrogels were prepared using CRGD, oligoCOL, oligoFN, and oligoVN concentrations of $50 \mu \mathrm{g} / \mathrm{ml}$. The bar indicates $100 \mu \mathrm{m}$.

hAFCs could not be cultivated on PVA hydrogels with or without grafting of oligoCOL (an oligopeptide derived from collagen I [COL]) when the hydrogels had an elasticity less than $20 \mathrm{kPa}$ (P-6, P-12, P-6-oligoCOL, and P-12-oligoCOL). By contrast, hAFCs could expand on
PVA hydrogels with or without grafting of ECM-derived oligopeptides (CRGD, oligoCOL, oligoVN, and oligoFN) when the dishes had an $E^{\prime}>20 \mathrm{kPa}$ (the cross-linking time of PVA was at least $24 \mathrm{~h}$ with and without the grafting of ECM-derived oligopeptides) and on TCPS plates 
(elastic moduli=3-12 GPa). P-6h-cRGD, P-6h-oligoFN, and P-6h-oligoVN hydrogels supported hAFC proliferation, whereas P-6h and P-6h-oligoCOL did not. On the basis of the previously mentioned results, oligoCOL seems to be a less favorable nanosegment compared with cRGD, oligoFN, and oligoVN for the expansion of hAFCs. Of the PVA hydrogels with $E^{\prime}$ values ranging between 13.2 and $30.2 \mathrm{kPa}$ (cross-linking time $=6-48 \mathrm{~h}$ ), hAFCs cultured on PVA hydrogels immobilized with cRGD (P-Xh-cRGD) and oligoFN (P-Xh-oligoFN) showed similar doubling times compared with those cultured on TCPS (Figure 7). Therefore, $\mathrm{P}$ - $X \mathrm{~h}$-cRGD and P-Xh-oligoFN hydrogels $(X=6-48)$ were found to be appropriate to evaluate the effects of hydrogel stiffness on hAFC culture.

\subsection{Culture of human ES and iPS cells on P-oligoVN hydrogel dishes}

Human ES and iPS cells were cultured on P-Xh-oligoVN hydrogels [oligoVN is an oligopeptide derived from vitronectin (VN)] with different elasticities to evaluate the effects of hydrogel stiffness on the expansion of stem cells and their ability to maintain pluripotency because vitronectin

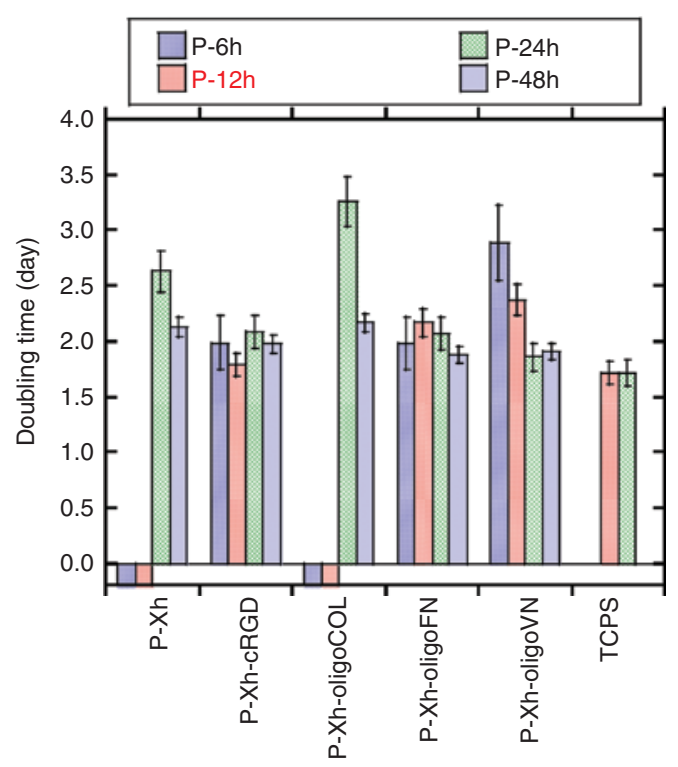

Figure 7: Doubling times of hAFCs cultured on soft P-6 (left column), P-12 (the second column from left), P-24 (the third column from left), and stiff P-48 (right column) hydrogels immobilized with cyclic RGD (CRGD) or ECM-derived oligopeptides (oligoCOL, oligoFN, and oligoVN), without modification, and on TCPS dishes. P-Xh-CRGD, $\mathrm{P}$-Xh-oligoCOL, P-Xh-oligoFN, and P-Xh-oligoVN hydrogels were prepared with CRGD, oligoCOL, oligoFN, and oligoVN concentrations of $50 \mu \mathrm{g} / \mathrm{ml}$. The data are expressed as the mean \pm standard deviation of three independent measurements. and oligoVN coatings on cell culture dishes have been reported to help maintain human ES and iPS cell pluripotency $[18,37,38]$. When screening to evaluate biomaterials for human ES and iPS cell culture, cell attachment is one of the first factors that must be evaluated, followed by assessments of cell colony morphology and cell colonies showing no differentiation, as the use of appropriate biomaterials facilitate the development and maintenance of these human ES and iPS cell characteristics [5, 6, 32]. Figure 8 shows the morphologies of human ES cells (WA09) and human iPS cells (HPS0077) cultured on P-Xh-oligoVN dishes with different elasticities (P-1h-oligoVN, P-6h-oligoVN, P-12h-oligoVN, P-24h-oligoVN, and P-48h-oligoVN hydrogels) and on dishes coated with Matrigel at passage 1. The ES and iPS cells did not attach well to the softest P-1h-oligoVN hydrogels, whereas the ES cells did attach well to the PVA hydrogels with elasticities greater than $12 \mathrm{kPa}$ (i.e. the P-6h-oligoVN, P-12h-oligoVN, P-24h-olig$\mathrm{oVN}$, and P-48h-oligoVN hydrogels). These results indicate that the use of biomaterials with minimum elasticity is necessary to allow the attachment of human ES cells.

Human ES cell (WA09) pluripotency was evaluated by immunostaining to detect the expression of pluripotent proteins after culture on P-24h-oligoVN hydrogel dishes in xeno-free conditions (i.e. in Essential 8 culture medium) for 10 passages. The results are shown in Figure 9. The pluripotent proteins Nanog, Sox2, Oct3/4, SSEA-4, Tra-160, and Tra-1-81 were expressed in these cells.

To evaluate human ES cell pluripotency, it is necessary to determine whether these cells can differentiate into cells derived from all three germ layers in vitro (via EB formation assay). Therefore, human ES cells (WA09) were cultured on P-24h-oligoVN hydrogels under xeno-free conditions for 10 passages and subsequently cultured in suspension using ultralow protein binding dishes to facilitate EB formation (Figure 10A). Differentiated human ES cells were immunostained with antibodies against $\beta$ III-tubulin (ectoderm), SMA (smooth muscle actin and mesoderm), and AFP (alpha-fetoprotein and endoderm). The results are shown in Figure 10B. The cells were able to differentiate into cells expressing BIII-tubulin, SMA, and AFP, indicating that they maintained their pluripotency after culture on P-24h-oligoVN hydrogel dishes.

\section{Discussion}

In the current study, we demonstrated that several different cell types, including colon cancer cells, hHSCs, hAFCs, and human ES and iPS cells, can be cultured 


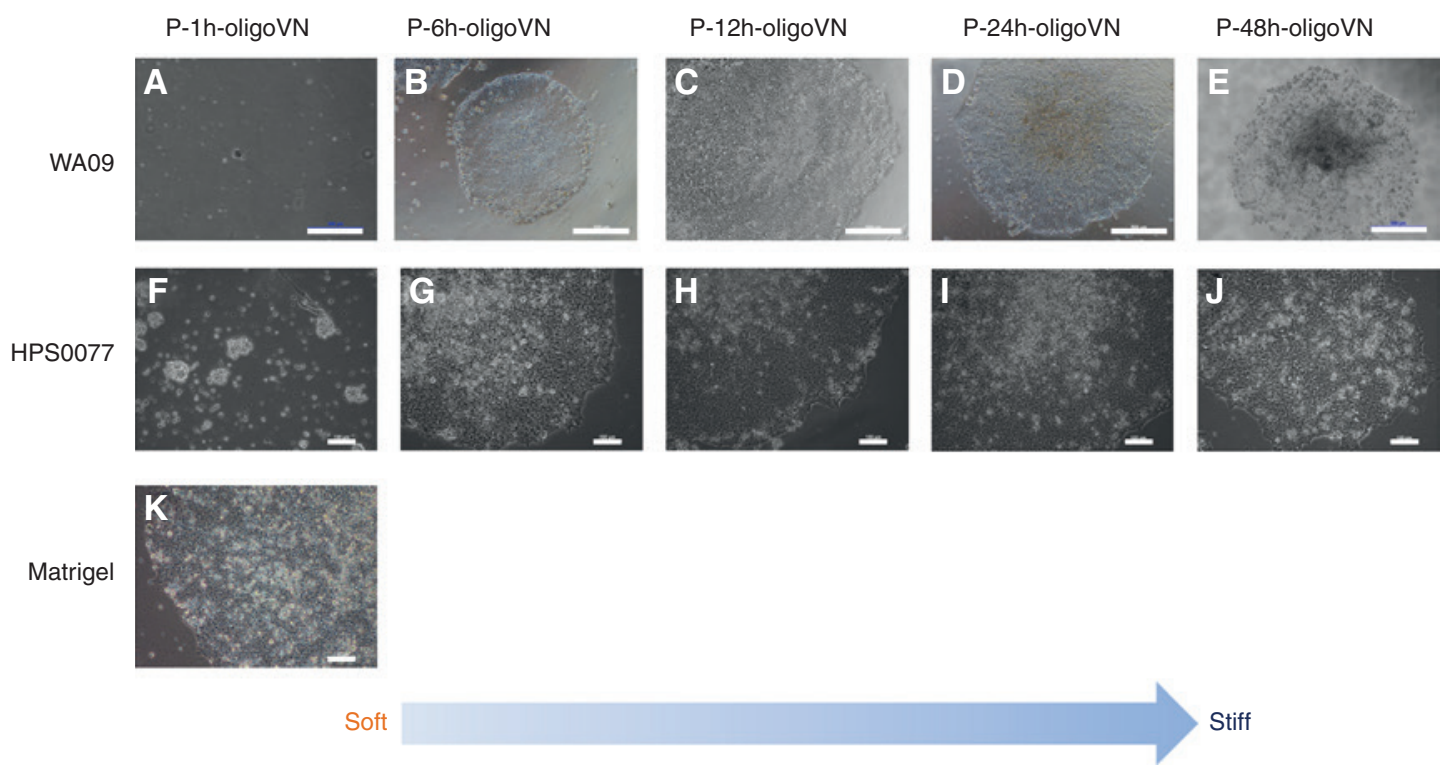

Figure 8: Morphologies of human ES (WA09, A-E) and human iPS (HPS0077, F-J) cells cultured on P-1h-VN (A and F), P-6h-VN (B and G), P-12h-VN (C and H), P-24h-VN (D and I), and P-48h-VN (E and J) hydrogels and Matrigel-coated dishes (K) after 5 days in culture at passage 1. $\mathrm{P}$-24h-oligoVN was prepared with an oligoVN concentration of $1000 \mu \mathrm{g} / \mathrm{ml}$. The bar indicates $100 \mu \mathrm{m}$.
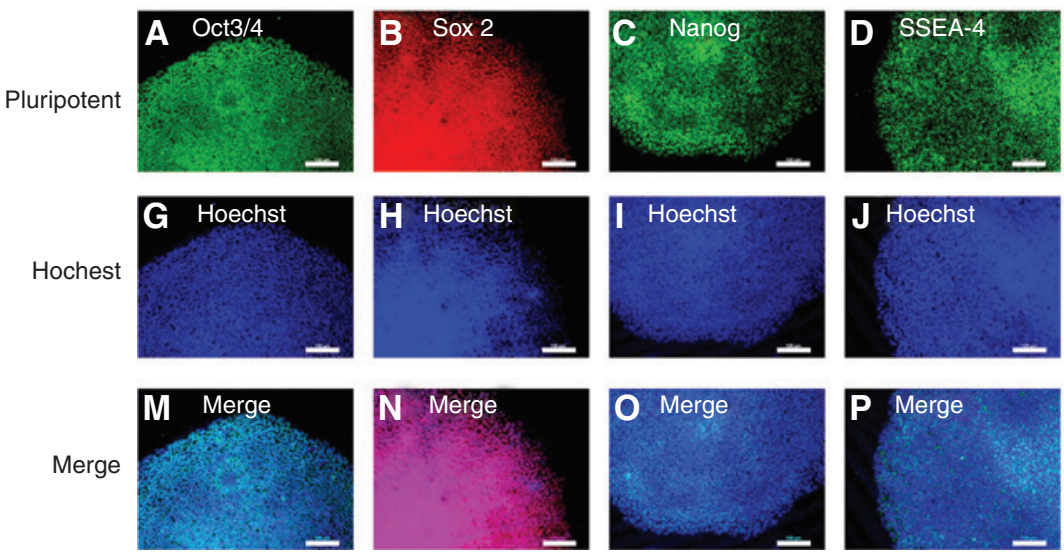
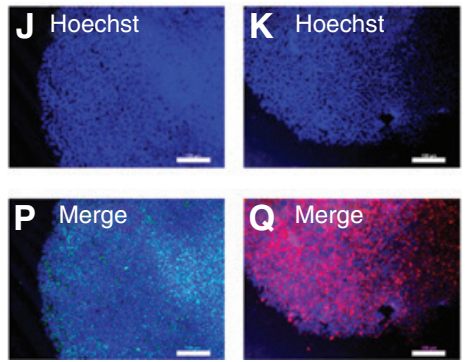
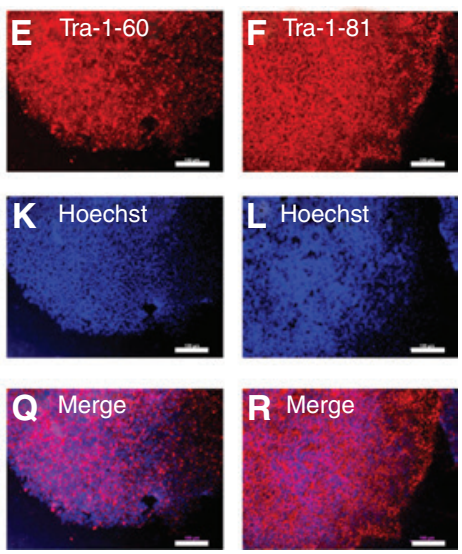

Figure 9: Characterization of human ES (WA09) cell pluripotency after culture on P-24h-oligoVN hydrogels based on the expression of pluripotent proteins. Pluripotent protein expression in the human ES (WA09) cells was analyzed by immunostaining after culture on $\mathrm{P}$-24h-oligoVN dishes under xeno-free conditions for 10 passages. The P-24h-oligoVN dishes were prepared with an oligoVN concentration of $500 \mu \mathrm{g} / \mathrm{ml}$. (A) Oct3/4, (B) Sox2, (C) Nanog, (D) SSEA-4, (E) Tra-1-60, (F) Tra-1-81, and (G-L) Hoechst staining of the human ES cells used in $(A-F)$ and $(M-R)$ merged images of the immunostaining $(A-F)$ and Hoechst staining $(G-L)$. The bar indicates $100 \mu \mathrm{m}$.

on PVA hydrogels immobilized with and without FN or ECM-derived oligopeptides. Cell proliferation depended on the nanosegments used to immobilize the hydrogels (i.e. ECM-derived oligopeptides and ECMs) as well as on hydrogel elasticity. Table 2 shows the varying levels of cell proliferation measured after culture on the PVA hydrogels investigated in this study. Relatively stiff hydrogels (P-24h and P-48h) supported the proliferation of colon cancer cells, hHSCs, and hAFCs. By contrast, human ES and iPS cells could not be cultured on unmodified PVA hydrogels, regardless of their elasticity. To culture these cells, it was necessary to graft oligoVN to the hydrogels (Figure 8).

Historically, polyacrylamide hydrogels have been used to evaluate the effects of cell culture biomaterial elasticity on stem cell proliferation and differentiation [22, 25, 26]. However, human ES and iPS cells cannot maintain their pluripotency on polyacrylamide hydrogels. Table 3 summarizes the results of previous studies that have investigated how cell culture biomaterial elasticity affects stem cell culture and differentiation. Recently, polymers 

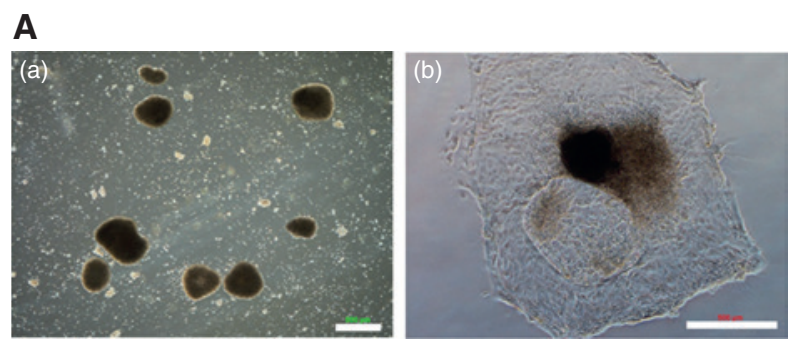

\section{B}

\section{(a) AFP}

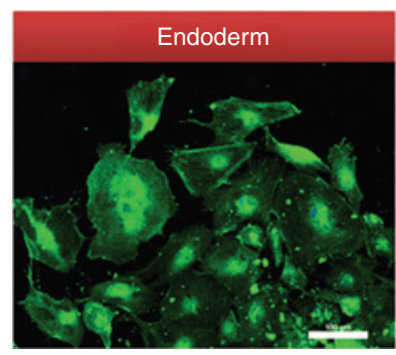

(b) SMA

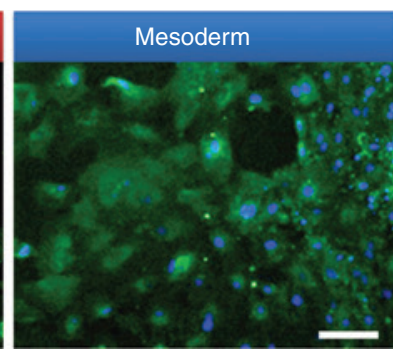

(c) BIII-Tubulin

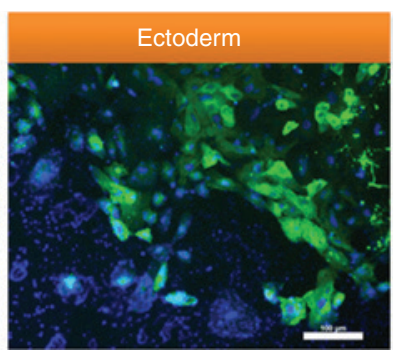

Figure 10: Characterization of human ES (WA09) cell differentiation ability in vitro after culture on P-24h-oligoVN hydrogels for 10 passages. The P-24h-oligoVN hydrogels were prepared using an oligoVN concentration of $500 \mu \mathrm{g} / \mathrm{ml}$. (A) Morphologies of EBs differentiated from human ES (WA09, $a$ and b) cells after culture on P-24h-oligoVN hydrogels under xeno-free conditions for 10 passages. (B) Immunostaining of an endoderm protein (a, AFP, green), a mesoderm protein (b, SMA, green), and an ectoderm protein (c, $\beta$ III-tubulin, green) in human ES (WA09) cells after culture on P-24h-10oligoVN hydrogels under xeno-free conditions for 10 passages. Hoechst-stained nuclei are shown in blue. The bar indicates $100 \mu \mathrm{m}$.

Table 2: The proliferation of cells cultured on PVA hydrogels. ${ }^{\text {a }}$

\begin{tabular}{|c|c|c|c|c|c|c|c|}
\hline Cells & $\begin{array}{l}\text { P-0.5h } \\
(10.3 \mathrm{kPa})\end{array}$ & $\begin{array}{l}\text { P-1h } \\
(10.3 \mathrm{kPa})\end{array}$ & $\begin{array}{l}\text { P-6h } \\
(15.8 \mathrm{kPa})\end{array}$ & $\begin{array}{l}\text { P-12h } \\
(21.2 \mathrm{kPa})\end{array}$ & $\begin{array}{l}\text { P-24h } \\
(25.3 \mathrm{kPa})\end{array}$ & $\begin{array}{l}\text { P-48h } \\
(30.4 \mathrm{kPa})\end{array}$ & TCPS \\
\hline \multicolumn{8}{|l|}{ Colon cancer cells } \\
\hline Colo205 & $P$ & $P$ & G & G & E & E & $\mathrm{E}$ \\
\hline LoVo & $\mathrm{N}$ & $\mathrm{N}$ & G & G & G & G & $E$ \\
\hline Colo-NCU1 & $\mathrm{N}$ & $\mathrm{N}$ & $\mathrm{P}$ & $P$ & $P$ & G & $\mathrm{E}$ \\
\hline \multicolumn{8}{|l|}{ Stem cells } \\
\hline UC-HSCS & E & $\mathrm{E}$ & E & & $\mathrm{E}$ & & $\mathrm{E}$ \\
\hline hAFCs & $\mathrm{N}$ & $\mathrm{N}$ & $P$ & G & G & E & $\mathrm{E}$ \\
\hline Human ES cells & $\mathrm{N}$ & $\mathrm{N}$ & $\mathrm{N}$ & $\mathrm{N}$ & $\mathrm{N}$ & $\mathrm{N}$ & $\mathrm{N}$ \\
\hline Human iPS cells & $\mathrm{N}$ & $\mathrm{N}$ & $\mathrm{N}$ & $\mathrm{N}$ & $\mathrm{N}$ & $\mathrm{N}$ & $\mathrm{N}$ \\
\hline
\end{tabular}

a"E”, “G”, “P”, and “N” indicates excellent, good, poor, and no culture, respectively.

other than polyacrylamide have been used to evaluate the effects of cell culture biomaterial elasticity on cell culture. These polymers include biomaterials made of (a) natural polymers, such as alginate [39], agarose [39], chitosan [40, 41], hyaluronic acid [42], fibrin [43], silk [45, 46], elastin [45], gelatin [44], and collagen [47]; (b) synthetic polymers, such as PDMS [25], poly(glycolic acid) [48], poly( $\varepsilon$ caprolactone) [48], poly(lactic-co-glycolic acid) [48], poly(L-lactic acid) [48], poly(ethyleneglycol) [49, 50], and poly(hydroxyethyl methacrylate) [51]; and (c) polymerinorganic hybrids, such as silk/hydroxyapatite (HAp) [54],
gelatin/HAp [55], gelatin/ $\beta$-tricalcium phosphate [52], polycaprolactone/HAp [53], and collagen/carbon nanotubes [56].

Bone ECM is a natural composite that contains HAp and collagen. Several researchers have prepared polymerinorganic hybrid scaffolds using Hap, such as silk/HAp and gelatin/Hap scaffolds [54, 55]. Mattei et al. [55] prepared composite gelatin/HAp scaffolds with varying HAp contents along with elasticity-matched HAp-free gelatin scaffolds as a control. Human periosteal-derived progenitor cells (PDPCs) were cultivated on the scaffolds for 


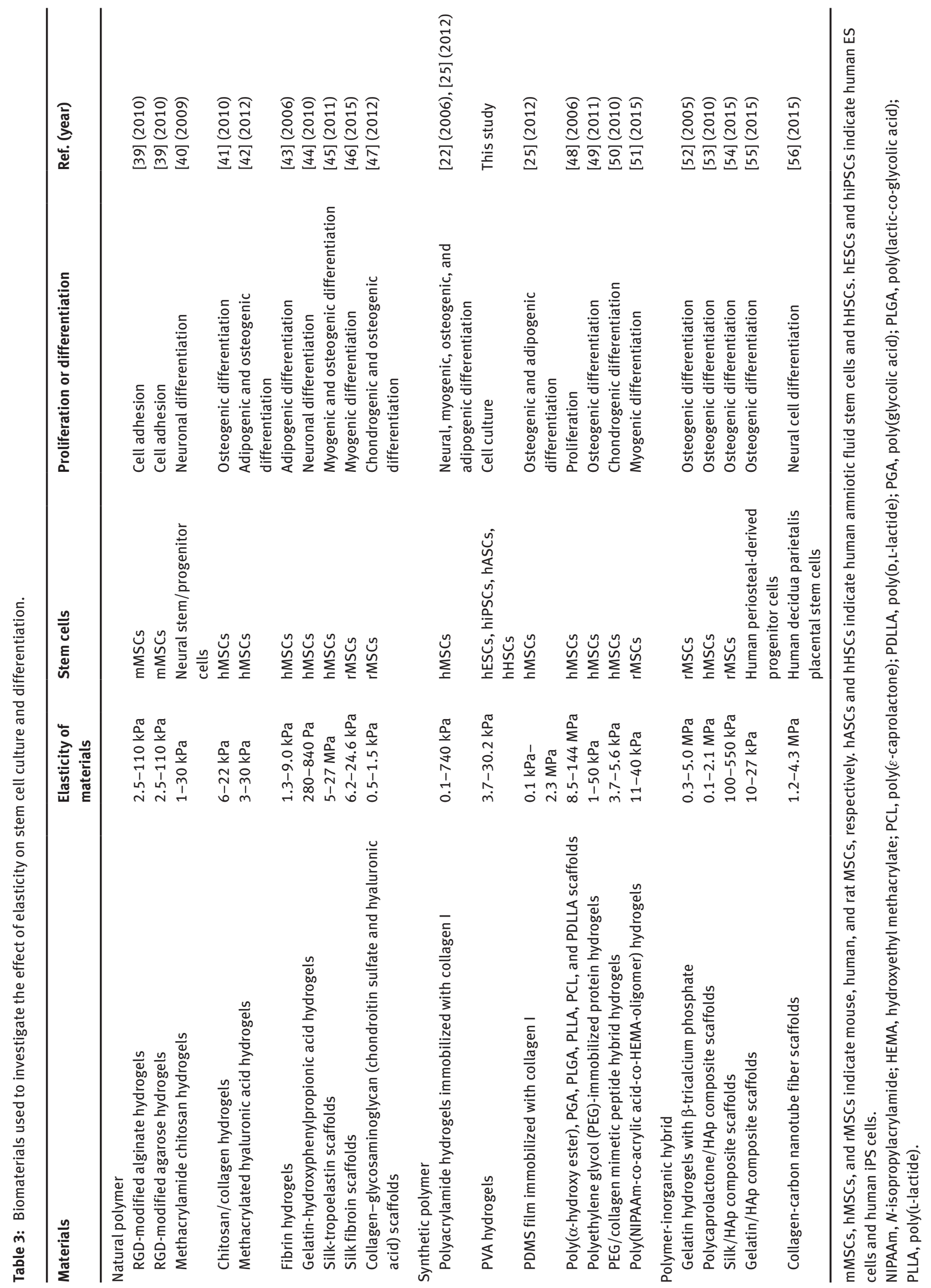


7 days. They showed that both the stiffness and the Hap contents of the scaffolds contributed to the osteogenic differentiation of the PDPCs, indicating the role of elasticity in triggering the osteogenic gene expression and the role of HAp in facilitating the differentiation process, particularly at high content of HAp [55].

\section{Conclusions}

The elasticities of the PVA hydrogels investigated in this study can be easily modified by adjusting their cross-linking time. In addition, these hydrogels can be covalently immobilized with a variety of ECMs and ECM-derived oligopeptides via aqueous phase reactions. Therefore, PVA hydrogels immobilized with or without FN or ECMderived oligopeptides should be excellent candidate of cell culture biomaterials for investigations into the effects on the culture and differentiation of various stem cell types.

Acknowledgments: This work was partially supported by the LandSeed Hospital project (NCU-LSH-105-A-001) and the Cathay General Hospital Project (105CGH-NCU-A3, CGH-MR-A10404, and CGH-MR-A10405). This research was also supported by the Ministry of Science and Technology, Taiwan, under grant number 104-2221-E-008-107-MY3 and 105-2119-M-008-006. A Grant-in-Aid for Scientific Research (15K06591) from the Ministry of Education, Culture, Sports, Science, and Technology of Japan is also acknowledged. The authors extend their sincere appreciation to the Deanship of Scientific Research at King Saud University for its funding of this research through research group project no. RG-1435-065.

\section{References}

[1] Thomson JA, Itskovitz-Eldor J, Shapiro SS, Waknitz MA, Swiergiel JJ, Marshall VS, Jones JM. Science 1998, 282, 1145-1147.

[2] Takahashi K, Tanabe K, Ohnuki M, Narita M, Ichisaka T, Tomoda K, Yamanaka S. Cell 2007, 131, 861-872.

[3] Yu J, Vodyanik MA, Smuga-Otto K, Antosiewicz-Bourget J, Frane JL, Tian S, Nie J, Jonsdottir GA, Ruotti V, Stewart R, Slukvin II, Thomson JA. Science 2007, 318, 1917-1920.

[4] Higuchi A, Ling QD, Kumar SS, Munusamy MA, Alarfaj AA, Chang Y, Kao SH, Lin KC, Wang HC, Umezawa A. Lab. Invest. 2015, 95, 26-42.

[5] Higuchi A, Ling QD, Ko YA, Chang Y, Umezawa A. Chem. Rev. 2011, 111, 3021-3035.

[6] Higuchi A, Ling QD, Kumar S, Munusamy M, Alarfajj AA, Umezawa A, Wu GJ. Prog. Polym. Sci. 2014, 39, 1348-1374
[7] Kao TC, Lee HH, Higuchi A, Ling QD, Yu WC, Chou YH, Wang PY, Kumar S, Chang Y, Chen HY, Chang Y, Chen DC, Hsu ST. J. Biomed. Mater. Res. B. Appl. Biomater. 2014, 102, 463-476.

[8] Higuchi A, Ling QD, Chang Y, Hsu ST, Umezawa A. Chem. Rev. 2013, 113, 3297-3328.

[9] Higuchi A, Ling QD, Kumar SS, Chang Y, Alarfaj AA, Munusamy MA, Murugan K, Hsu ST, Umezawa A. J. Mater. Chem. B. 2015, 3, 8032-8058.

[10] Kim HN, Jiao A, Hwang NS, Kim MS, Kang DH, Kim DH, Suh KY. Nanotopography-guided tissue engineering and regenerative medicine, Adv. Drug Delivery Rev. 2013, 65, 536-558.

[11] Kim DH, Provenzano PP, Smith CL, Levchenko A. J. Cell Biol. 2012, 197, 351-360.

[12] Orza Al, Mihu C, Soritau O, Diudea M, Florea A, Matei H, Balici S, Mudalige T, Kanarpardy GK, Biris AS. Nanotechnology 2014, 25, 065102

[13] Kim DH, Lipke EA, Kim P, Cheong R, Thompson S, Delannoy M, Suh KY, Tung L, Levchenko A. Proc. Natl. Acad. Sci. U.S.A. 2010, 107, 565-570.

[14] Villa-Diaz LG, Nandivada H, Ding J, Nogueira-de-Souza NC, Krebsbach PH, O’Shea KS, Lahann J, Smith GD. Nat. Biotechnol. 2010, 28, 581-583.

[15] Irwin EF, Gupta R, Dashti DC, Healy KE. Biomaterials 2011, 32, 6912-6919.

[16] Brafman DA, Chang CW, Fernandez A, Willert K, Varghese S, Chien S. Biomaterials 2010, 31, 9135-9144.

[17] Zhang R, Mjoseng HK, Hoeve MA, Bauer NG, Pells S, Besseling $R$, Velugotla S, Tourniaire G, Kishen RE, Tsenkina Y, Armit C, Duffy CR, Helfen M, Edenhofer F, de Sousa PA, Bradley M. Nat. Commun. 2013, 4, 1335.

[18] Prowse AB, Doran MR, Cooper-White JJ, Chong F, Munro TP, Fitzpatrick J, Chung TL, Haylock DN, Gray PP, Wolvetang EJ. Biomaterials 2010, 31, 8281-8288.

[19] Sugii S, Kida Y, Kawamura T, Suzuki J, Vassena R, Yin YQ, Lutz MK, Berggren WT, Izpisua Belmonte JC, Evans RM. Proc. Natl. Acad. Sci. U.S.A. 2010, 107, 3558-3563.

[20] Rodin S, Domogatskaya A, Strom S, Hansson EM, Chien KR, Inzunza J, Hovatta O, Tryggvason K. Nat. Biotechnol. 2010, 28, 611-615.

[21] Miyazaki T, Futaki S, Suemori H, Taniguchi Y, Yamada M, Kawasaki M, Hayashi M, Kumagai H, Nakatsuji N, Sekiguchi K, Kawase E. Nat. Commun. 2012, 3, 1236.

[22] Engler AJ, Sen S, Sweeney HL, Discher DE. Cell 2006, 126, 677-689.

[23] Wen JH, Vincent LG, Fuhrmann A, Choi YS, Hribar KC, TaylorWeiner H, Chen S, Engler AJ. Nat. Mater. 2014, 13, 979-987.

[24] Murphy WL, McDevitt TC, Engler AJ. Nat. Mater. 2014, 13, 547-557.

[25] Trappmann B, Gautrot JE, Connelly JT, Strange DG, Li Y, Oyen ML, Cohen SMA, Boehm H, Li B, Vogel V, Spatz JP, Watt FM, Huck WT. Nat. Mater. 2012, 11, 642-649.

[26] Rowlands AS, George PA, Cooper-White JJ. Am. J. Physiol. Cell Physiol. 2008, 295, C1037-C1044.

[27] Kumar SS, Hsiao JH, Ling QD, Dulinska-Molak I, Chen GP, Chang Y, Chang Y, Chen YH, Chen DC, Hsu ST, Higuchi A. Biomaterials 2013, 34, 7632-7644.

[28] Peng IC, Yeh CC, Lu YT, Muduli S, Ling QD, Alarfaj AA, Munusamy MA, Kumar SS, Murugan K, Lee HC, Chang Y, Higuchi A. Biomaterials 2016, 76, 76-86. 
[29] Wang PY, Lee HHC, Higuchi A, Ling QD, Lin HR, Li HF, Kumar SS, Chang Y, Alarfaj AA, Munusamy MA, Chen DC, Hsu ST, Wang HC, Hsiao HY, Wu GJ. J. Mater. Chem. B 2015, 3, 3858-3869.

[30] Higuchi A, Huang SC, Shen PY, Ling QD, Zhao JK, Chang Y, Wang HC, Bing JT, Hsu ST. Curr. Nanosci. 2011, 7, 893-901.

[31] Higuchi A, Yang ST, Li PT, Tamai M, Tagawa Y, Chang Y, Chang Y, Ling QD, Hsu ST. J. Membrane Sci. 2010, 351, 104-111.

[32] Higuchi A, Lin FL, Cheng YK, Kao TC, Kumar SS, Ling QD, Hou CH, Chen DC, Hsu ST, Wu GJ. J. Taiwan Inst. Chem. Eng. 2014, 45, 295-301.

[33] Lu HE, Tsai MS, Yang YC, Yuan CC, Wang TH, Lin XZ, Tseng CP, Hwang SM. Exp. Cell Res. 2011, 317, 1895-1903.

[34] Higuchi A, Kao SH, Ling QD, Chen YM, Li HF, Alarfaj AA, Munusamy MA, Murugan K, Chang SC, Lee HC, Hsu ST, Kumar SS, Umezawa A. Sci. Rep. 2015, 5, 18136.

[35] Feng Q, Chai C, Jiang XS, Leong KW, Mao HQ. J. Biomed. Mater. Res. A. 2006, 78, 781-791.

[36] Jiang XS, Chai C, Zhang Y, Zhuo RX, Mao HQ, Leong KW. Biomaterials 2006, 27, 2723-2732.

[37] Higuchi A, Wang CT, Ling QD, Lee HH, Kumar SS, Chang Y, Alarfaj AA, Munusamy MA, Hsu ST, Wu GJ, Umezawa A. Sci. Rep. 2015, 5, 10217.

[38] Melkoumian Z, Weber JL, Weber DM, Fadeev AG, Zhou Y, Dolley-Sonneville P, Yang J, Qiu L, Priest CA, Shogbon C, Martin AW, Nelson J, West P, Beltzer JP, Pal S, Brandenberger R. Nat. Biotech. 2010, 28, 606-610.

[39] Huebsch N, Arany PR, Mao AS, Shvartsman D, Ali OA, Bencherif SA, Rivera-Feliciano J, Mooney DJ. Nat. Mater. 2010, 9 , 518-526.

[40] Leipzig ND, Shoichet MS. Biomaterials 2009, 30, 6867-6878.
[41] Wang, L, Stegemann, JP. Biomaterials 2010, 31, 3976-3985.

[42] Guvendiren M, Burdick JA. Nat. Commun. 2012, 3, 792.

[43] Ghajar CM, Blevins KS, Hughes CC, George SC, Putnam AJ. Tissue Eng. 2006, 12, 2875-2888.

[44] Wang LS, Chung JE, Chan PP, Kurisawa M. Biomaterials 2010, 31, 1148-1157.

[45] Hu X, Park SH, Gil ES, Xia XX, Weiss AS, Kaplan DL. Biomaterials 2011, 32, 8979-8989.

[46] Bai SM, Han HY, Huang XW, Xu WA, Kaplan DL, Zhu HS, Lu Q. Acta Biomater. 2015, 20, 22-31.

[47] Murphy CM, Matsiko A, Haugh MG, Gleeson JP, O’Brien FJ. J. Mech. Behav. Biomed. 2012, 11, 53-62.

[48] Li WJ, Cooper JA, Mauck RL, Tuan RS. Acta Biomater. 2006, 2, 377-385.

[49] Gobaa S, Hoehnel S, Roccio M, Negro A, Kobel S, Lutolf MP. Nat. Methods 2011, 8, 949-955.

[50] Liu SQ, Tian Q, Hedrick JL, Hui PJH, Ee PL, Yang YY. Biomaterials 2010, 31, 7298-7307.

[51] Xu YY, Li ZQ, Li XF, Fan ZB, Liu ZG, Xie XY, Guan JJ. Acta Biomater. 2015, 26, 23-33.

[52] Takahashi Y, Yamamoto M, Tabata Y. Biomaterials 2005, 26, 3587-3596.

[53] Roohani-Esfahani SI, Nouri-Khorasani S, Lu Z, Appleyard R, Zreiqat H. Biomaterials 2010, 31, 5498-5509.

[54] Huang XW, Bai SM, Lu Q, Liu X, Liu SS, Zhu HS. J. Biomed. Mater. Res. B 2015, 103, 1402-1414.

[55] Mattei G, Ferretti C, Tirella A, Ahluwalia A, Mattioli-Belmonte M. Sci. Rep. 2015, 5, 10778.

[56] Kim T, Sridharan I, Zhu BF, Orgel J, Wang R. Mat. Sci. Eng. C. Mater. 2015, 49, 281-289. 